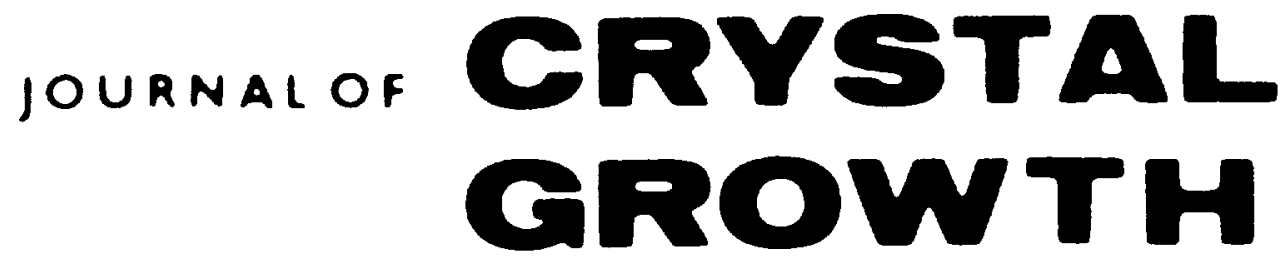

Journal of Crystal Growth 147 (1995) 83-90

Growth rates and interface shapes in germanium and lead tin telluride observed in-situ, real-time in vertical Bridgman furnaces

P.G. Barber ${ }^{\text {a }}{ }^{*}$, R.F. Berry ${ }^{\text {b }}$, W.J. Debnam ${ }^{\text {b }}$, A.L. Fripp ${ }^{\text {b }}$, G. Woodell ${ }^{\text {b }}$, R.T. Simchick ${ }^{\mathrm{c}}$

a Longwood College, Farmuille, Virginia 23909, USA

${ }^{b}$ NASA Langley Research Center, Hampton, Virginia 23681-00)1, USA

${ }^{c}$ Lackheed Corporation, Hampton, Virginia 23666, USA

Received 22 February 1994; manuscript received in final form 23 September 1994

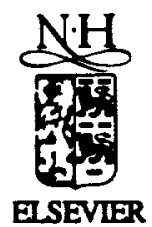




\section{EDITORIAL BOARD}

II SCHILBIR (P'rincipal Fdilor)

Dept Mitterials Science.

School Anpl. Soi. \& Technol.

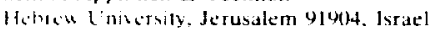

lolefux: $+972-2 \cdot 6668014$

$K K L R$

(RN1C CNRS, Campus L.uminy, Case 913

p. 13ax Marscille cedex 9. France

lelkfux $+33-41-418916$

BAVDO (Sidperconductitity)

l.at of Solid Siate (hemistry

Imst for Chemical Research, Kyoto Univ.

Uji. Kyoto-fu 611, Japan

Teletite $+\times 1-774-335080$

A BARONNEI (Indastrial, Biolexical and Holecular (nstals)

CRMC" CNRS, Compus Luminy, Case 913

F. 1.3288 Marseille Cedex 9, France

Tclefax: +33.91 .418916$

K.W. BENZ. (Micrograitit, Rlectronic Materials)

Kristallographisches Inst.. Universitä

Hethelstr. 25, D.79104 Freiburg. Germany

Tefefax: + 49-761-203 4369

G. M. BLOM (Liquid Phase Epitaxy)

Philips Laboratories, 345 Scarborough Ruad

Briarcliff Manor, NY 10510, USA

Telefax: + 1-914-945 0375

A.A. CHERNOV (Kinetics of Cystallization)

Inst. Crystallography, Acad. of Sciences

teninskii Prosp., Moscow 117333, Russian Fed

Telefax: + 7-095-1351011

J. ('HIKAWA (Perfection of Crystals) Faculty of Science, Himeji Insi. Technology Harima Gurden City, Kamigori-chyo Hyogo 678.12, Japan

A.Y. CHO (Molecular Beam Epitaxy) Room [C-323, AT\& T Bell Laboratories

Murray Hill, NJ 07974-2070, USA

Telefax: + 1-908-582 2043

B. COCKAYNE (Retien Arricles, IOCG News)

DRA Malvern, St. Andrews Road

Great Malvern. Worcs. WR14 3PS, UK

Telefax: + 44-684-844540

S.R. CORIELL (Theon)

A153 Materials

Natl. Inst of Standards \& Technol.

(juithershurgh, MD 2(K9O)-(KKI). USA

D BI.WELL. (Priority Communication

Superionductirity)

Hughes Aircrafl Company

P.O. Box H, M/S A240\%, sin) Suneriur Avenuc

New Port Beach, CA 92658-89018, USA

Telefax: + 1-714-7592868
R. FEIGEISON

(tr Materials Res., 105 McCullough Bldg.

Stanford Univ., Stanford, CA 94305-4045, USA

Telefix: + 1.415-72.3 3044

1. NISHINAGA

Dept. Electronic Engineering, University of Tokyo

7-1-1, Hongo, Bunkyo-ku, Tokyo I13, Japan

Telefax: + 81-3-5684-3974

\section{ASSOCIATE EDITORS}

ME. GLICKSMAN (Solidification)

School of Engineering, Mater. Eng. Dept.

Rensselaer Polytechnic Inst.

Troy, NY 12180-3590, USA

Telefax: $+1.518-2768854$

M.A.G. HALLIWELL ( $X$-ray Diffraction)

Philips Analytical X-ray, Lelyweg

7602 EA Almeto. Netherlands

K.A. JACKSON (Theory)

Arizona Materials Laboratory

4715 E Fort Lowell Road, Tucson, AZ 85712, USA

L. KALDIS (Chemical Trunsport)

Institut für Festkörperphysik. ETH

Hönggerberg, CH-8093 Zürich, Switzerland

Telefax: + 41-1-371 5989

S. KIMURA (Oxide Crystals)

National Inst. Res. Inorg. Materials

1-1 Namiki, Tsukuba, Ibaraki 305, Japan

Telefax: + 81-298-52 7449

T.F. KUECH (Thin Films and Electronic and Optical Devices)

Dept. Chemical Engineering

Univ. Wisconsin-Madison

Madison, WI 53706, USA

Telefax: + 1-608-2625434

H. KUKIMOTO (Thin Films, Epitaxy)

Imaging Science \& Eng. Lab.

Tokyo Inst. of Technology

4259 Nagatsuda, Midori-ku

Yokohama 227, Japan

Telefax: + 81-45-921-1492

A McPLERSON (Protein Growth)

Dent. Biochemistry, Univ. of California

Riverside, CA 92521, USA

Telefax: +1.909 .7873790$

J.B MULLIN (Semiconductors)

LMC, "The Hoo", Brockhill Road

West Malvern, Worcs. WR 14 4DI., UK

Teletax: + 44-6\&4-575 591

K PLOOG (Molecular Beam Epitaxy)

Paul-Drude-Inst. für Festkörperelektronik

Hatusvengteiplat7 5-7. D-10117 Berlin, Germany

Telefax $+49-30-20377201$
D.T.J. HURLE

11.H. Wills Physics Laboratory

Univ. Bristol, Tyndall Avenue

Bristol RSB 1TL, UK

\section{G.B. STRINGFELLOW}

Depl. Malerials Science, 304 EMRO

University of Utah

Salt l.ake City, UT 84112 , USA

Telefax: + 1.801-581 4816

F. ROSENBERGER (Vapor Growth, Fluid

Dynamics

Center for Microgravity and Materials Research

Univ. Alabama, Huntsville, AL 35899, USA

relefax: + 1-205-895 6791

R.W. ROUSSEAU (Solution Growth

Indisinal (rystallizution)

School of Chemical Engineering

Georgia Institute of Technology

Atlanta, GA 30332-0100, USA

relefax: + 1-404-894 2866

K. SATO (Biocystallization and

Organic Crystals)

Fac. Applied Biological Science

Hiroshima Univ.

Higashi-Hiroshima 724, Japan

Telefax: + 81-824-227062

L.F. SCHNEEMEYER (Superconducricity,

Oxtdes. Notel Materials)

Room 1A-363. AT \& T Bell Laboratories

Murray Hill, NJ 07974-2070, USA

Telefax: + 1-908-582 2521

D.W. SHAW (Semiconductors, Epitaxy, Decices)

Texas Instruments Inc., P.O. Box 655936, MS 147

Dallas, TX 75265, USA

Telefax: + 1-214-095 5539

I. SUNAGAWA (Morphology and Minerals)

3-54-2 Kashiwa-cho, Tachikawa-shi

Tokyo 190, Japan

Tclefax: + 81-425-35 3637

T. SUREK (Materials for Energy Coni ersion and Photorollaics)

National Renewable Energy Lab.

1617 Cole Bivd., Golden, CO 80401, USA

Telefax: + 1-303-231 1030

G. VAN TENDELOO (Electron Micruscopy. Fullerenes, Superconducticuty)

University of Antwerp, RUCA

Groenenborgerlaan 171

B-2020 Antwerp, Belgium

Telef $a x$ : +32-3.2180 217

A.F. WITT (Semiconducror (nystals)

Dept of Metallurgy \& Materials Science

Massachusetts Institute of Technology

Cambridge, MA 02139, USA

Telefax: + 1-617.253 $5 \times 27$

Technical Editors: J. Hanraads and A. Koch, Fisevier/North-Holland, P.O. Box 103, 1000 AC Amsterdam, Netherlands,

Telefax: + 31-20-485 2775, E-mail: koch $a$ elsevier.nt

EIsevier Science B.V.: Alt rights reserved. No part of this publication may be reproduced, stored in a retrieval system or transmitted in any form or by any means, electronic, mechanical, photocopying. recording of utherwise, without the written permission of the publisher. Elsevier Science B.V., P.O. Box 103 , 1000 AC Amsterdam, Netherlands.

Siscial regulatons for authors - Upon ucceptance of an article by the journal, the author(s) will be asked to transfer copyright of the article to the publisher. This transfer will ensure the widest possible dissemination of information.

Spertul regalations for readers in the USA - This journal has been registered with the Copyright Clearance Centet. Inc. Consent is given for copying of articles for persmal or internal use, or for the personal use of specific clients. This consent is given on the condition that the copier pays through the Center the per-copy fee stated in the code on the first pagc of each article fur copying beyond that permitted by Sections 107 or 108 of the US Copyright Law. The appropriate fee should the forwarded with a copy of the first page of the article to the Copyright Clearance Center, Inc., 222 Rosewood Drive, Danvers, MA 01923, USA. If no code appears in an article, the author has nut given broad consent to copy and permission to copy must be obtained directly from the author. The fee indicated on the first page of an article in this issue will apply retroactivcly to all articles published in the journal, regardless of the year of publication. This consent does not extend to other kinds of copying, such as for general distribution, resale, advertising and promolion purposes, or for creating new collective works Special written permission must be obtained from the puhlisher for such copying.

Vo responsibility is assumed by the Publisher for any injury and/or damage to persons or property as a matter of products liability negligence or othenwise, or from iny use or operation of any methods, products, instructions or ideas contained in the material herein. Although all advertising material is expected to conform w ethical standards, inclusion in this publication does not constitute a guarantee or endorsement of the yuality or value of such product or of the claims

CS mailing notice - Journal of Crystal Growth (ISSN 0022-0248) is published semimonthly by Elsevier Science, Molenwerf 1, P.O. Box 211, 1000 AE Amsterdam, Netherlands. Annual subscription price in the USA is US $\$ 5305$ (valid in North, Central and South America only), including air speed delivery. Second class postage paid at Jamaica NY 11431 .

ISA POSTMASTERS: Send address changes to Journal of Crystal Growth, Publications Expediting, Inc., 200 Meacham Avenue, Elmont NY 11003 . Airfreight and mailing in the USA by Publications Expediting.

PRINTED IN THE NETHERLANDS 


\title{
Growth rates and interface shapes in germanium and lead tin telluride observed in-situ, real-time in vertical Bridgman furnaces
}

\author{
P.G. Barber ${ }^{a, *}$, R.F. Berry ${ }^{\text {b }}$, W.J. Debnam ${ }^{\text {b }}$, A.L. Fripp ${ }^{\text {b }}$, G. Woodell ${ }^{\text {b }}$, \\ R.T. Simchick ${ }^{c}$ \\ a Longwood College, Farmitile, Virginia 23909, USA \\ ${ }^{\text {' }}$ NASA Langley Research Center, Hampton, Virginia 23681-0001, USA \\ 'Lockheed Corporation, Hampton, Virginia 23666, USA
}

Received 22 February 1994; manuscript received in final form 23 September 1994

\begin{abstract}
Using the advanced technology developed to visualize the melt-solid interface in low Prandtl number materials. crystal growth rates and interface shapes have been measured in germanium and lead tin telluride semiconductors grown in vertical Bridgman furnaces. The experimental importance of using in-situ, real time observations to determine interface shapes, to measure crystal growth rates, and to improve furnace and ampoule designs is demonstrated. The interface shapes observed in-situ, in real-time were verified by quenching and mechanically induced interface demarcation, and they were also confirmed using machined models to ascertain the absence of geometric distortions. Interface shapes depended upon the interface position in the furnace insulation zone, varied with the nature of the crystal being grown, and were dependent on the extent of transition zones at the ends of the ampoule. Actual growth rates varied significantly from the constant translation rate in response to the thermophysical properties of the crystal and its melt and the thermal conditions existing in the furnace at the interface. In the elemental semiconductor germanium the observed rates of crystal growth exceeded the imposed translation rate, but in the compound semiconductor lead tin telluride the observed rates of growth were less than the translation rate. Finally, the extent of ampoule thermal loading influenced the interface positions, the shapes, and the growth rates.
\end{abstract}

\section{Introduction}

\subsection{Technology to visualize melt-solid interface}

To be economically useful, semiconductor crystals must be of very high purity, available in preferred crystal habits, and have a high degree of perfection. Preparing such materials demands

\footnotetext{
${ }^{*}$ Corresponding author.
}

careful control of the conditions of growth including the rate of growth and the shape of the melt-solid interface. These are important factors that affect the growth conditions in both semiconductors made from pure elements as well as those prepared from compound alloys. In the latter material the growth conditions affect the compositional distribution and the concomitant uniformity of the bandgap. To increase the range of available electronic properties for future applications, single crystals of ever more complex com- 
pound semiconductors will be needed, thus increasing the importance of accurate determinations of crystal growth rates and melt-solid interface shapes.

Witt et al. demonstrated in 1978 that Peltier pulsing could be successfully used to mark the melt-solid interface periodically during the growth of doped semiconductors. This method requires the post-processing of the grown crystal in order to make the interface demarcation lines visible [1].

To better understand the growth process, the experimental conditions governing growth, and the relationship between interface shape and crystal perfection in semiconductors, an advanced radioimaging technology was developed at the NASA Langley Research Center to enable the direct visualization of the melt-solid interface inside a Bridgman furnace. Semiconductors are opaque to visible light, and Bridgman furnaces are constructed from dense materials, which are also opaque to visible light. To penetrate the furnace and sample, it is necessary to use X-rays if the sample is not very dense or to use $\gamma$-rays if it is too dense for the lower energy X-rays. In a series of experiments beginning in 1986, this technology was developed first using high-contrast $X$-ray film, which enabled the interface position and shape to be determined [2]. The quality of these images was improved by incorporating image enhancement techniques [3]. The technology available at that time still required too long a period to enable the interface position data to be continuously determined accurately. The exposure time was greatly reduced by incorporating image intensification technology along with online image enhancement technology finally enabling in-situ, real-time images of the interface position and shape to be obtained. Each image can now be taken every $10 \mathrm{~s}$, which at a growth rate of $1 \mathrm{~cm} / \mathrm{h}$ allows only $28 \mu \mathrm{m}$ of growth. This is sufficiently small to allow sharp images of the interface to be recorded and to allow for the determination of interface position well within the resolution of the detector. Kakimoto et al. in Japan have developed a similar technology for observing interfaces and fluid flows in silicon grown in Czochralski furnaces [4,5]. The history of the development of this direct imaging technology is summarized in several articles [6].

\section{Verification tests of the technology}

\subsection{Instrumentation tested with known, machined standard interfaces}

This advanced imaging technology was first tested to verify that the images obtained corresponded to known positions and shapes without distortions. Calibration standards, which were fabricated from $250 \mu \mathrm{m}$ (i.e., 10 mil) diameter platinum wires placed at right angles and spaced $10.0 \mathrm{~mm}$ apart, were used to align the system, to calibrate it, and to verify the absence of any distortions. In addition, solids fabricated from copper and brass alloys were carefully machined, so that matching interfaces were observed with this equipment to ascertain that the observed shapes with cylindrical geometry also exhibited no distortions. The observed shapes corresponded to the measured physical shapes of the metal models to within one pixel, which is \pm 0.13 $\mathrm{mm}$ in the vertical.

\subsection{Interface shape compared to quenched results}

As a further verification of the system, a crystallization run was made on lead tin telluride quenched at mid growth. The melt-solid interface was observed via radiography during a similar crystallization. Fig. 1 compares the observed interface and the quenched one, which was visualized after cutting, polishing, and etching [7]. In this figure the interface deflection from the quenched and that for the real-time data are plotted together as functions of the radial position. The non-dimensional interface temperatures for these runs are given in the figure by the function $T_{\mathrm{f}}$, which is the ratio of the difference between the interface temperature and the temperature of the cold zone, $T_{1}-T_{c}$, and the difference between the hot and cold zones of the furnace, $T_{\mathrm{h}}-T_{\mathrm{c}}$.

For these data the fit is good near the edges of the cylindrical sample, but there is a significant 


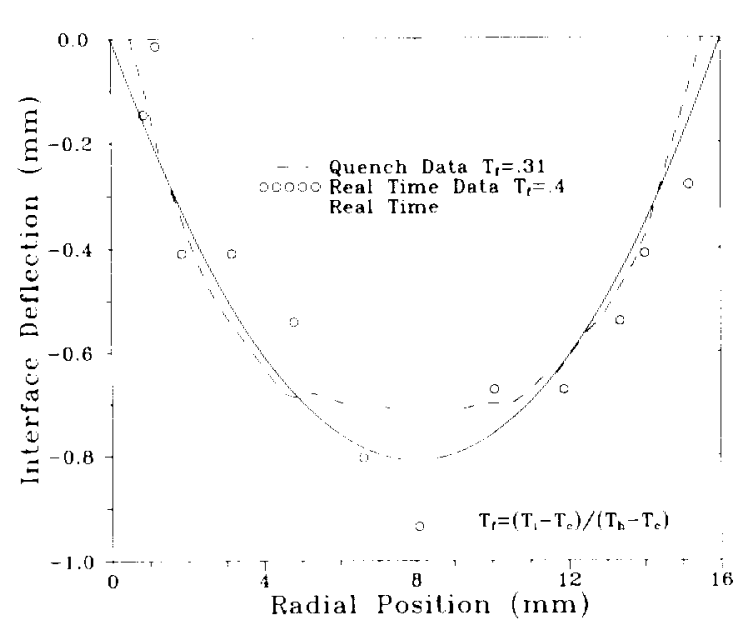

Fig. 1. Real-time shapes compared with quenched shapes in lead tin telluride.

difference between the two interface shapes near the central core of the sample. This apparent discrepancy is due to the small amount of rapid crystal growth that occurs, before interfacial breakdown, during the quenching process. When the ampoule is suddenly dropped into water to cool it quickly from about $900^{\circ} \mathrm{C}$ to room temperature, a small amount of time is required for the heat to be conducted from the core of the sample. While this is happening, the observed, small amount of growth occurs. The melt-solid interface shape observed in situ, in real-time gives a more accurate representation of the shape during growth.

As the melt-solid interface moves within the furnace adiabatic layer, it changes its shape due to slight changes in the thermal contours at different locations within the furnace. It has been observed that when the interface is near the lower, colder zone of the furnace, it assumes a concave shape. When the interface is near the upper, hotter zone of the furnace, it assumes a convex shape. Only when the interface is in the adiabatic region of the furnace midway between the hot and cold zones of the furnace does it assume a flat shape. The change in these thermal contours is a consequence of the differences in thermal conductivities of each phase in the hot and cold zones of the furnace. These thermal profiles were explained in several publications [8-18], and they have been observed in additional quench studies $[5,19]$.

\section{Crystal growth results}

\subsection{Dual nature of the problem}

When semiconductors are grown from melts, their commercial utility is dependent upon their compositional uniformity and the crystal perfection. These two properties of the materials depend upon the rate of crystal growth and the shape of the melt-solid interface during growth. Slow growth with a flat interface traditionally results in semiconducting crystals with the most uniform properties. To better understand those experimental parameters that influence these two aspects of growth, the interface was observed during growth in germanium and in lead tin telluride.

\subsection{Rate of growth}

Using radioimaging technology the melt-solid interface is directly observed during crystal growth, and the actual growth rates of germanium and lead tin telluride were determined. The data are summarized in Figs. 2, 3, and 4, which demonstrate that the rate of crystal growth only approximates the impressed ampoule translation rate for germanium and lead tin telluride. In the upper portion of these figures the observed positions of the melt-solid interfaces are plotted as functions of time of growth. Since the furnace and the detection systems are fixed with respect to each other, the actual crystal growth is the sum of the ampoule movement and the observed interfacial movement within the furnace. Differentiation of these curves gives the rate of growth, and these instantaneous growth rates are plotted as functions of total crystal length in the lower portions of the three Figs. 2, 3, and 4. The actual growth rate in these semiconductors varies over the course of the run.

The crystal growth rates illustrated in Fig. 2 reflect the situation occurring from an unseeded 
sample of germanium, which begins its growth with a first-to-freeze region following a deep supercooling. In germanium samples the actual crystal growth rate always exceeds the translation rate. Over the course of the experiment, the melt-solid interface in germanium changes its position with respect to the furnace gradually moving toward the upper, hot zone.

The crystal growth rate occurs differently if the growth begins from a seed, as illustrated in the two parts of Fig. 3. As with the previous figure, the upper portion summarizes the interface position as a function of time. The actual growth rate plotted as a function of crystal length
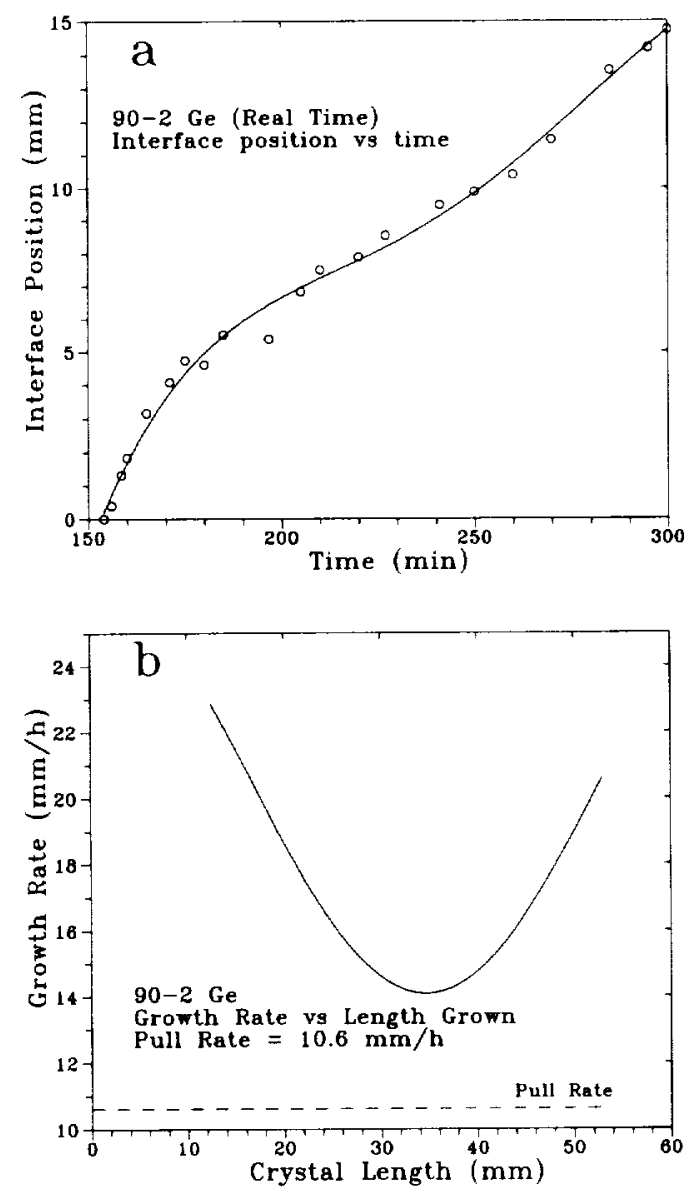

Fig. 2. (a) Melt-solid interface position as a function of time and (b) the actual growth rate as a function of crystal length in unseeded germanium.
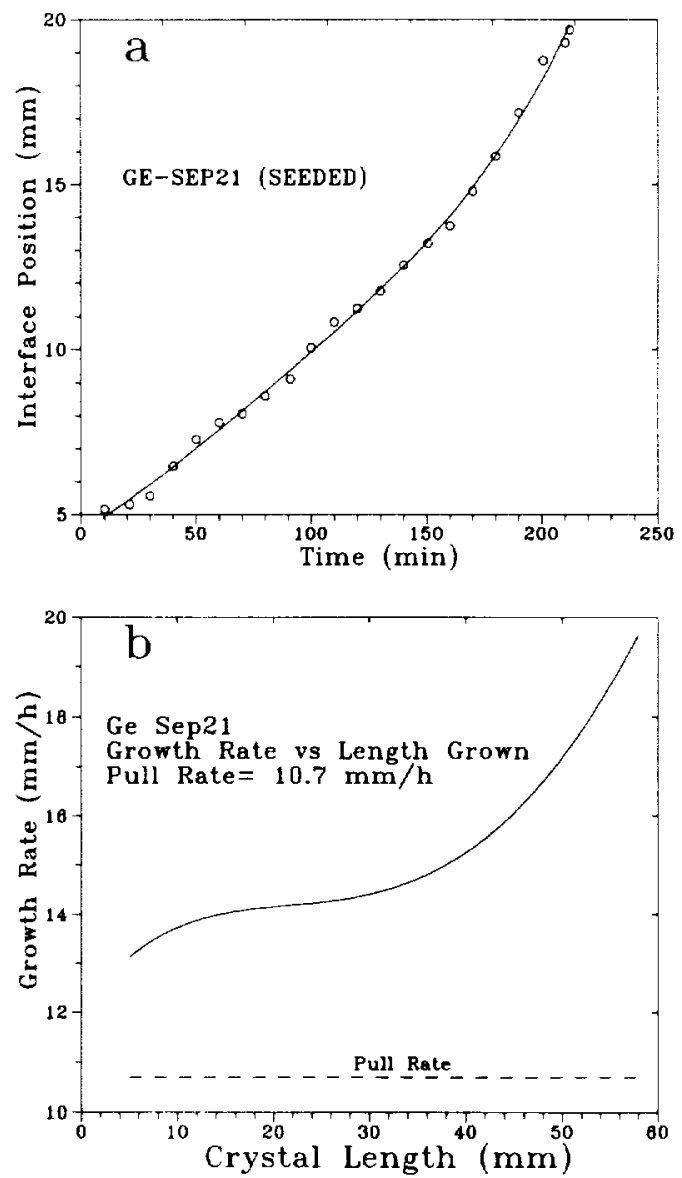

Fig. 3. (a) Melt-solid interface position as a function of time and (b) the actual growth rate as a function of crystal length in seeded germanium.

is shown in the lower portion of Fig. 3. As expected with seeded growth, the crystal quickly begins to grow without the extensive period of supercooling that precedes nucleation. As with unseeded growth in germanium, the growth rate exceeds the translation rate, and the interface position moves up in the insulation zone of the furnace toward the hot zone.

Similar data recorded for the unseeded growth of the compound semiconductor lead tin telluride are shown in Fig. 4. The position versus time data are in the upper graph, while the growth rate versus crystal length is in the lower graph of this figure. This material has a much smaller period 

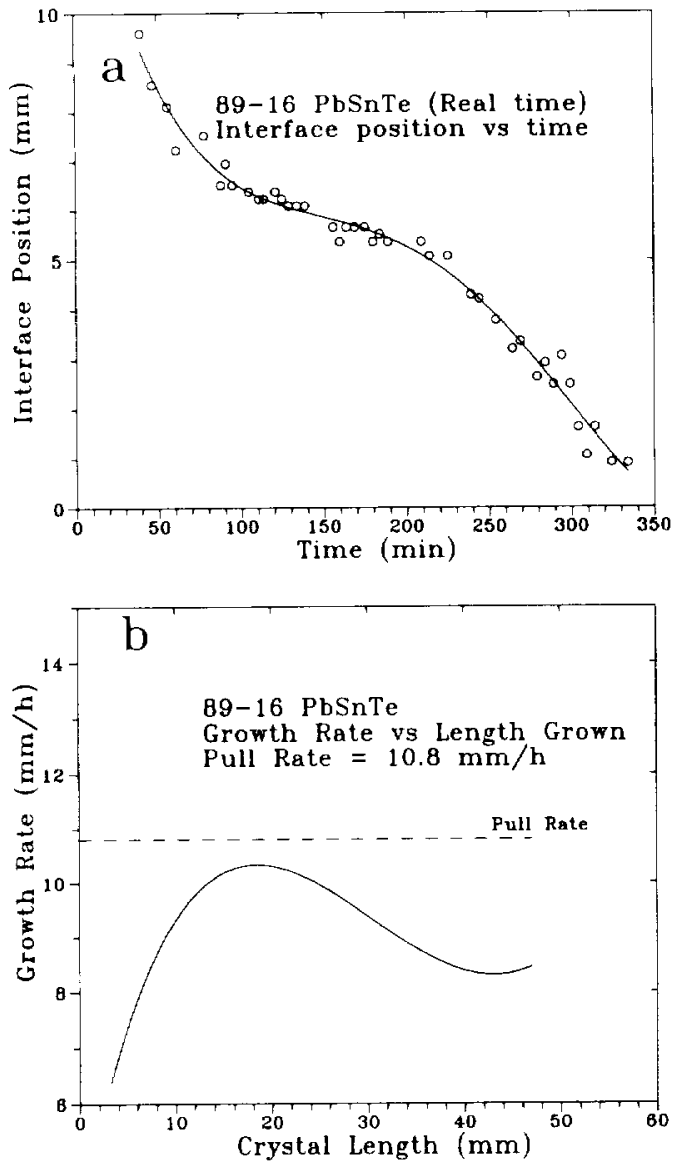

Fig. 4. (a) Melt-solid interface position as a function of time and (b) the actual growth rate as a function of crystal length in unseeded lead tin telluride.

of supercooling and nucleates more readily than does germanium under the same crystal growth conditions. As occurs in the germanium, the actual crystal growth rate in lead tin telluride varies over the course of the growth and never equals the translation rate of the ampoule. Unlike the situation in the Bridgman growth of germanium, the growth rate of the compound semiconductor lead tin telluride is less than the translation rate, and the melt-solid interface position gradually moves down toward the cold zone of the furnace. Interfaces move due to changes in heat transfer between ampoule and furnace and due to changes in the solidification temperature, if any, during the growth.

The objective of the thermally loaded versus no-loaded runs was to try to hold steady the heat transfer between ampoule and furnace. An effect in the direction expected was observed, but the thermal conductivity for germanium is approximately an order of magnitude greater than that for quartz. Thus, the observed difference between the two types of runs was not as great as anticipated. Since the thermal conductivity for lead tin telluride is about that of quartz, there should not be a significant movement of the interface due to thermal conductivity considerations. There will, however, be a change of position due to changes in the melting point. This happens because tin is selectively excluded during crystallization of lead tin telluride. The tin concentration of the melt slowly increases over the course of each run, and the melting point decreases as growth proceeds [20]. It is important to observe that, after an initial thermal transient, in neither material does the crystal growth rate ever equal the ampoule translation rate any time during the run, and the discrepancy is greater in the growth of germanium than in lead tin telluride. The advanced radioimaging technology makes detailed observations of melt-solid interface positions and actual growth rates available to crystal growers.

\subsection{Interface shapes}

The shape of the melt-solid interface in germanium changes during a crystal growth run. This is anticipated from the gradual movement of the melt-solid interface in the insulation zone during crystal growth. The shapes were observed in real-time over the course of crystallization in an ampoule containing germanium, and they are superimposed together on one graph shown in Fig. 5. The extent of curvature has been exaggerated by being multiplied by ten in this figure, so that both the curvatures and the interface positions can be displayed on the same graph. Since the melt-solid interface in germanium moves toward the upper, hot zone of the furnace as the crystal grows, the shape of the melt-solid inter- 


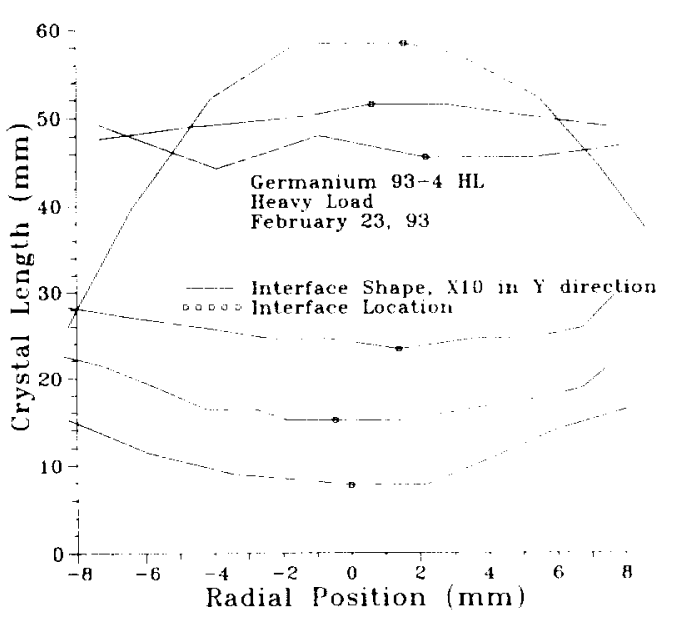

Fig. 5. Shape of the melt-solid interface in germanium changes with the length of the crystal.

face in germanium changes from concave to convex as it migrates from near the cold zone to near the hot zone in the Bridgman furnace. The curvature approaches a $2 \mathrm{~mm}$ deflection in the $16 \mathrm{~mm}$ diameter sample. The melt-solid interface is flat only near the middle of the isothermal liner, and the interface is in this position only for a small portion of the crystallization. These observations are consistent with other experimental studies using interface demarcation and with theoretically predicted shapes $[6-18,21]$. A comparison of results from radioimaging and mechanically induced interface demarcations in gallium-doped germanium, $\mathrm{Ge}(\mathrm{Ga})$, demonstrates that the interface positions and shapes from both techniques are to be superimposed.

These results demonstrate the importance of using imaging technology to visualize the interface shape and position during crystallization, so that the furnace conditions and thermal fields can be adjusted to optimize the region of ideal, flat shape.

\subsection{Furnace design and ampoule thermal loading}

This radioimaging technology was also used to test the effect of the extent of ampoule loading on the crystallization rate and interface shapes in germanium. To obtain temperatures during the crystallization, $0.8 \mathrm{~mm}$ OD sheathed, type $\mathrm{K}$ thermocouples are bundled and placed in grooves cut into the $1 \mathrm{~mm}$ thick walls of the quartz ampoules. The thermocouples are cemented in place using ceramic cement. Fig. 6 shows a photograph of the heavily loaded and the "no-load" ampoules. Each germanium sample is $16 \mathrm{~mm}$ in diameter and approximately $8 \mathrm{~cm}$ in length. In all experimental runs the lower isothermal liner was the colder of the two, and the thermocouples were attached to the ampoule from the lower end, which passed through the hotter zone of the furnace. This array of platinum-clad thermocouples affects the thermal field in the ampoule, thus altering the semiconductor growth rates and shapes. To as-

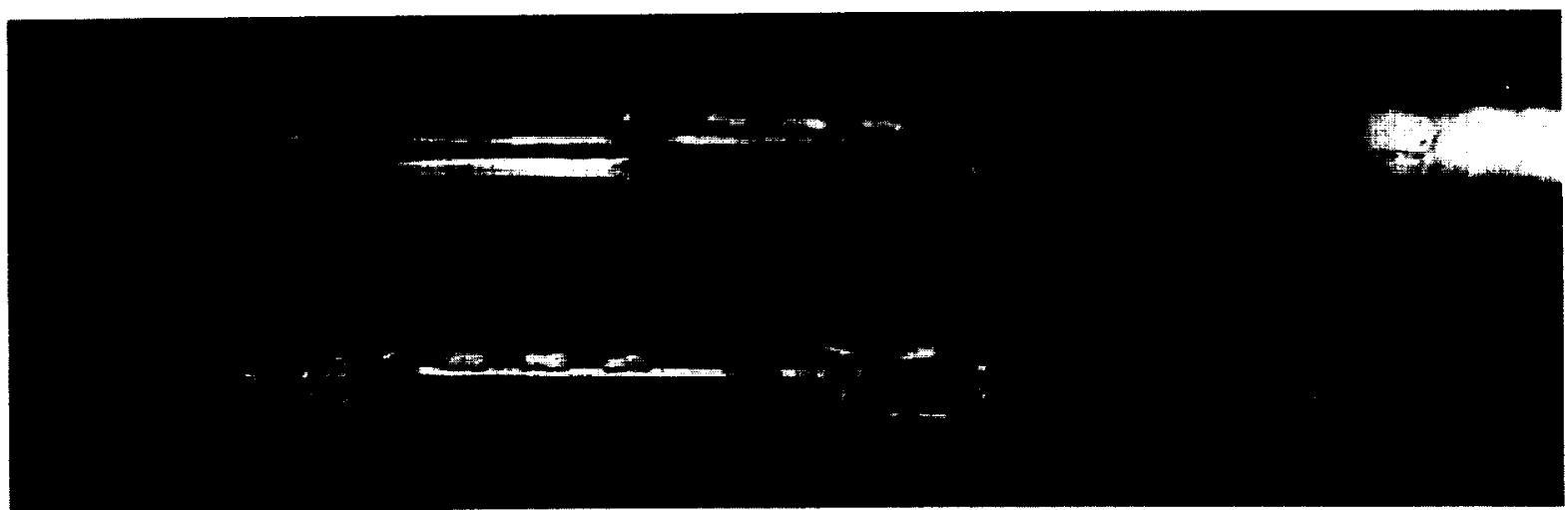

Fig. 6. "Heavily loaded" and "no-load" fused silica ampoules with thermocouples cemented in place. Each ampoule is $16 \mathrm{~mm}$ in diameter. 

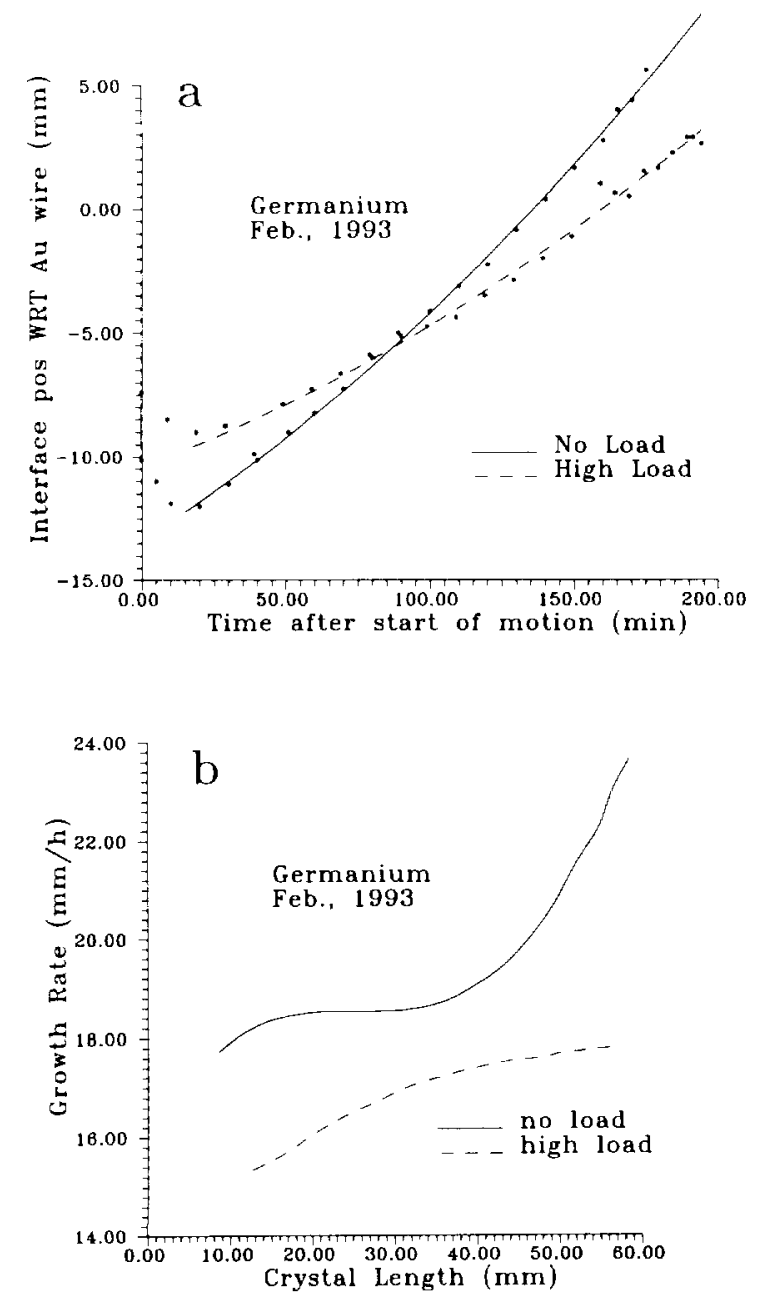

Fig. 7. (a) Melt-solid interface position as a function of time and (b) the actual growth rate as a function of crystal length in seeded germanium using a high-load ampoule and a no-load ampoule.

certain the effect of the thermal loading, a series of experimental runs were made with the normal heavy loading and with greatly reduced loading identified as "no load". In the latter case only one, type $K$ thermocouple was attached to the ampoule.

Fig. 7 summarizes the observed interface position and growth rate data for seeded growth of germanium in a normal, high load ampoule and a no-load ampoule. In both ampoule configurations the growth rates were consistently greater than the translation rates after the initial thermal transient period. Although the furnace thermal configurations in the two ampoule designs were similar, the average growth rate in the no-load case was significantly greater than in the high-load ampoule. The growth rate in the no-load ampoule was approximately $60 \%$ greater than the translation rate, while in the high-load ampoule the growth rate was approximately $40 \%$ greater than the translation rate. The most obvious difference in growth rates occurred in the last centimeter of crystallization. In the no-load configuration the crystal growth rate increased significantly, while in the high-load configuration, it leveled off. The no-load ampoule also exhibited a greater variation in growth rate over the course of the $6 \mathrm{~cm}$ of growth than was exhibited in the high-load case. Finally, the melt-solid interface shapes also differed in the two ampoule configurations with the high-load one resulting in significantly greater interface curvature than the no-load case.

These data suggest that faster growth with a greater probability of melt-solid interfaces having less curvature occurs in ampoules that are not carrying high thermal loads such as those from metal-clad thermocouples and that significant improvement in crystal growth may be possible by slight modifications of ampoule designs $[22,23]$.

\section{Conclusion}

By using radioimaging technology, direct observation of the melt-solid interface inside Bridgman furnaces is possible throughout the growth. After testing the technology to be sure that there were no geometric distortions of distances or shapes, the technology was used to determine the interface shapes and crystal growth rates in germanium and lead tin telluride samples. The actual rates of crystal growth and the interface shapes were found to exceed the furnace translation rate in the germanium samples, but to be less than the furnace translation rate in the lead tin telluride samples. The interface shape depends upon its position in the furnace, which changes during the run. Furnace and ampoule 
design affects both the crystal growth rates and the interface shapes. The flattest interfaces with the fastest crystal growth rates were obtained when the ampoules were designed to minimize the thermal loading resulting from the positioning of the thermocouples.

The results of this series of studies demonstrate the utility and the importance of using direct observations of melt-solid interfaces to obtain in-situ, real-time data on crystal growth rates and interface shapes.

\section{Acknowledgement}

One of the authors, P.G.B., gratefully acknowledges the support received through an Advanced Technology Development Grant from NASA, NAG-1-627.

\section{References}

[1] A.F. Witt, H.C. Gatos, M. Lichtensteiger and C.J. Herman, J. Electrochem. Soc. 125 (1978) 1832.

[2] P.G. Barber, R.K. Crouch, A.L. Fripp, Jr., W.J. Debnam, Jr. and R.F. Berry, Jr., J. Crystal Growth 74 (1986) 228.

[3] P.G. Barber, R.F. Berry, W.J. Debnam, A.L. Fripp, Y. Huang, K. Stacy and R.T. Simchick, J. Crystal Growth 97 (1989) 672.

[4] K. Kakimoto, M. Eguchi, H. Watanabe and T. Hibiya, J. Crystal Growth 88 (1988) 365.
[5] K. Kakimoto, M. Eguchi, H. Watanabe and T. Hibiya, J Crystal Growth 94 (1989) 405.

[6] R.T. Simchick, S. Sorokach, A.L. Fripp, W.J. Debnam, R.F. Berry and P.G. Barber, in: Advances in X-Ray Analysis 35, Eds. C.S. Barrett et al. (Plenum, New York, 1992) pp. 1295-1300.

[7] Y. Huang, W.J. Debnam and A.L. Fripp, J. Crystal Growth 104 (1990) 315.

[8] C.E. Chang and W.R. Wilcox, J. Crystal Growth 21 (1974) 135.

[9] T.W. Clyne, J. Crystal Growth 50 (1980) 684.

[10] T.W. Clyne, J. Crystal Growth 50 (1980) 691

[11] C.E. Huang, D. Elwell and R.S. Feigelson, J. Crystal Growth 64 (1983) 441

[12] C.L. Jones, P. Capper, J.J. Gosney and I. Kenworthy, J. Crystal Growth $69(1984) 281$.

[13] C.A. Wang and A.F. Witt, J. Crystal Growth 66 (1984) 299.

[14] H. Potts and W.R. Wilcox, J. Crystal Growth 73 (1985) 350.

[15] G.C. Cheng, D. Elwell, R.S. Feigelson and C.E. Huang, J. Crystal Growth 73 (1985) 417.

[16] Y.M. Dakhoul, R. Farmer, S.L. Lehoczky and F.R. Szofran, J. Crystal Growth 86 (1988) 49.

[17] F.R. Szofran and S.L. Lehoczky, J. Crystal Growth 70 (1984) 349 .

[18] T. Jasinski and A.F. Witt. J. Crystal Growth 71 (1985) 295.

[19] P. Capper, J.J.G. Gosney, C.L. Jones and M.J.T. Quelch, J. Crystal Growth 63 (1983) 154.

[20] T.C. Harman, J. Non-Metals 1 (1973) 183.

[21] P.C. Sukanek, J. Crustal Growth 58 (1982) 208.

[22] J.A. Hubert, A.L. Fripp, Jr. and C.S. Welch, J. Crystal Growth 131 (1993) 75.

[23] J.A. Hubert, Numerical Thermal Analysis of a Sample of Germanium with a Centerline Capillary Tube in a Vertical Bridgeman (sic) Furnace, Thesis, Faculty of the School of Engineering and Applied Sciences, George Washington University (1992). 